CASO CLÍNICO

\title{
Mosaicismo de trisomía 13
}

\author{
Francisco Cammarata-Scalisi ${ }^{1 *}$, Dianora Araque ${ }^{1}$, Rosmary Ramírez $^{2}$, Luis Guaran ${ }^{3}$ y Gloria Da Silva ${ }^{1}$ \\ ${ }^{1}$ Unidad de Genética Médica, Departamento de Puericultura y Pediatría, Universidad de Los Andes, Mérida; ${ }^{2}$ Centro de Recuperación Nutricional \\ Infantil Dr. Pastor Oropeza, San Cristóbal, Táchira; ${ }^{3}$ Hospital Central de San Cristóbal, San Cristóbal, Táchira. Venezuela
}

\section{Resumen}

Introducción: La trisomía 13 es una alteración cromosómica con una incidencia de 1 en 10,000 a 20,000 nacimientos. Puede ocurrir de forma completa, parcial o en mosaicismo. Este último caso ocurre cuando, en un individuo, un porcentaje de células son trisómicas para el cromosoma 13 mientras que el resto son euploides, y corresponde solamente al 5\% de todos los casos. Los pacientes que padecen trisomía 13 presentan una expresividad variable, que va desde malformaciones graves con muerte temprana (fenotipo similar a la forma completa y más frecuente) hasta un desarrollo normal y pocos hallazgos dismórficos. Casos clínicos: Se presentan los hallazgos clínicos y citogenéticos de dos casos nuevos de mosaicismo de trisomía 13. Conclusiones: Se resalta la importancia del diagnóstico prenatal, los hallazgos clínicos y la evaluación médica interdisciplinaria, así como un asesoramiento genético oportuno.

Palabras clave: Trisomía 13. Mosaicismo. Diagnóstico prenatal. Clínica. Asesoramiento genético.

\section{Trisomy 13 mosaicism}

\section{Abstract}

Background: Trisomy 13 is a chromosomal alteration with an incidence of 1 in 10,000 to 20,000 births. It can occur completely, partially or in mosaicism; the latter occurs when a percentage of cells are trisomic for chromosome 13, while the rest are euploid in an individual and corresponds to only 5\% of all cases. Patients with trisomy 13 present a wide variable expressivity, ranging from severe malformations with early death (phenotype similar to the complete form and more frequent), to normal development and few dysmorphic findings. Case reports: The clinical and cytogenetic findings of two new cases of trisomy 13 mosaicism are described. Conclusions: The importance of prenatal diagnosis, clinical findings, and interdisciplinary medical evaluation is highlighted, as well as an appropriate genetic counseling.

Key words: Trisomy 13. Mosaicism. Prenatal diagnosis. Clinical. Genetic counseling.

Disponible en internet: 19-07-2019 Bol Med Hosp Infant Mex. 2019;76:246-250 www.bmhim.com 


\section{Introducción}

La trisomía 13 es una alteración cromosómica con una incidencia de 1 en 10,000 a 20,000 nacimientos ${ }^{1}$. Puede ocurrir de forma completa, parcial o en mosaicismo. La forma completa se presenta cuando tres copias del cromosoma 13 están presentes en todas las células de un individuo ${ }^{1,2}$. Esta forma se presenta en casi el $80 \%$ de los casos y la muerte de los pacientes que la padecen ocurre generalmente dentro de los primeros días a semanas de vida. La translocación más común es la $13 q 14 q^{3}$. En el mosaicismo, que corresponde solo al $5 \%$ de todos los casos de trisomía 13 , un porcentaje de células son trisómicas mientras que el resto son euploides ${ }^{4}$.

El fenotipo y la historia natural de la forma completa de la trisomía 13 se caracterizan por presentar holoprosencefalia, malformación de Dandy-Walker, microcefalia, aplasia cutis, microftalmia, labio-paladar hendido, higroma quístico, mielomenigocele, cardiopatía congénita, onfalocele, anormalidades urogenitales, polidactilia postaxial, calcáneo prominente y uñas hiperconvexas ${ }^{4,5}$. La muerte de los pacientes con trisomía 13, por lo general, es temprana, con una supervivencia del 5 al $10 \%$ posterior al año de edad ${ }^{5}$. En los sobrevivientes, sin embargo, el retraso mental puede ser de severo a profundo $0^{1,4}$. Por su parte, los pacientes con mosaicismo de trisomía 13 presentan expresividad variable ${ }^{4,6}$, desde malformaciones graves y muerte temprana (fenotipo similar a la forma completa) hasta un desarrollo normal y pocos hallazgos dismórficos ${ }^{2,3}$.

En este trabajo se presentan dos casos de mosaicismo de trisomía 13 con la finalidad de resaltar los hallazgos clínicos y enfatizar la importancia del diagnóstico prenatal y de la evaluación médica interdisciplinaria requerida para poder impartir un asesoramiento genético oportuno.

\section{Casos clínicos}

\section{Caso 1}

Recién nacida de sexo femenino referida por presentar dismorfia facial (labio-paladar hendido) y cardiopatía congénita (caso único en la familia). Madre de 28 años al momento de la concepción y su tercera gestación. El hermano mayor de la paciente falleció el día de su nacimiento por sufrimiento fetal agudo; la segunda hermana está sana, producto de unión no consanguínea. Durante el embarazo, a la madre se le realizaron los controles indicados. Presentó preeclampsia e infección de las vías urinarias al final de la gestación.

La paciente presentó diagnóstico prenatal de labio-paladar hendido. Nació por cesárea a las 35 semanas de gestación (SDG), con un peso al nacer de $2,200 \mathrm{~g}$ (percentil 10-50) ${ }^{7}$ y talla de $45 \mathrm{~cm}$ (percentil $10-25)^{8}$. Fue hospitalizada por la presencia de diversas malformaciones congénitas y riesgo de sepsis, para lo cual recibió tratamiento antibiótico. También presentó ictericia que ameritó fototerapia. En su evolución presentó paro cardiorrespiratorio en dos ocasiones, respondiendo a maniobras de reanimación.

Al examen físico, realizado a los 12 días de vida, presentó cianosis leve, microcefalia con perímetro cefálico $31.4 \mathrm{~cm}$ (percentil <3), fontanela anterior $2 \times 2 \mathrm{~cm}$, hipotelorismo ocular, fosa nasal única, ausencia de septum nasal, hendidura de labio-paladar media, cueIlo corto, pectus excavatum, soplo sistólico grado III/VI, abdomen batracoide; se detectó hipertonía en el examen neurológico.

La ecografía transfontanelar evidenció hemorragia de la matriz germinal grado III. No se encontraron otras alteraciones en línea media a nivel encefálico. En la evaluación por oftalmología se encontraron datos sugestivos de microcórnea y corectopia en ambos ojos. En la evaluación cardiovascular se detectó ducto arterioso persistente de $2.3 \mathrm{~mm}$ y comunicación interauricular de $3.6 \mathrm{~mm}$. La ecografía abdominorrenal mostró pielectasia izquierda. Los estudios de laboratorio evidenciaron plaquetopenia, hipoglucemia e hiperuricemia con acidosis metabólica no compensada. El estudio citogenético evidenció 46,XX[33]/47,XX,+13[7] en 40 metafases estudiadas.

La paciente presentó paro cardiorrespiratorio sin respuesta a las maniobras de reanimación avanzada. Falleció a los 18 días de nacida.

\section{Caso 2}

Recién nacida de sexo femenino referida por presentar retardo del crecimiento intrauterino, holoprosencefalia y dismorfia facial (labio-paladar hendido), caso único en la familia. Madre de 31 años al momento de la concepción y su cuarta gestación. Tres medios hermanos maternos: la hermana mayor y el segundo están sanos y la tercera falleció a los 28 días por cardiopatía congénita. La paciente es producto de unión no consanguínea. Durante el embarazo, a la madre no se le realizaron los controles indicados. Presentó amenaza de parto pretérmino desde las 32 SDG, además de que cursó con sagrado transvaginal y presentación fetal transversa. 


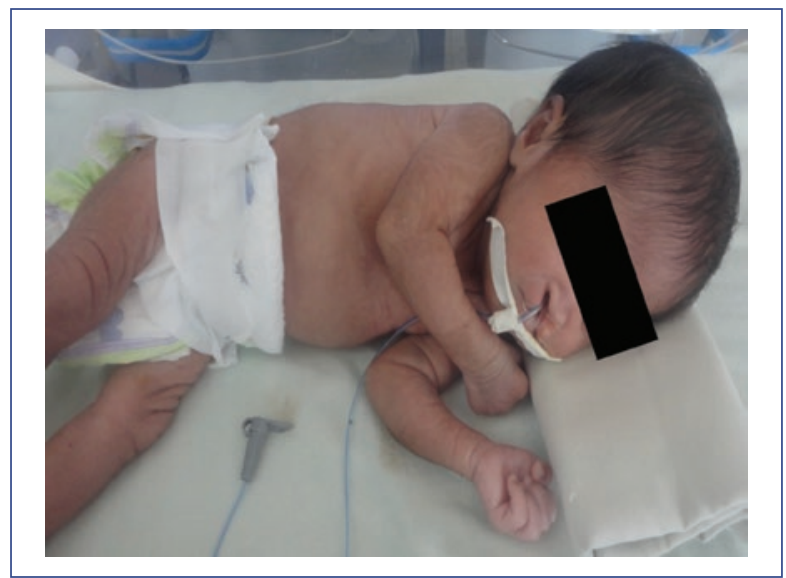

Figura 1. El caso 2 muestra microcefalia, hipotelorismo ocular, fosa nasal única, hipertricosis en la región frontal, hombros, tórax posterior y ambos brazos.

La paciente nació por vía vaginal a las 33 SDG, con un peso al nacer de $1,850 \mathrm{~g}$ (percentil 10-50) ${ }^{7}$ y talla de $44 \mathrm{~cm}$ (percentil 25-50). Presentó depresión neonatal moderada con prueba de Apgar de 5 y 7 puntos al primer y quinto minuto, respectivamente, lo cual requirió reanimación. Permaneció hospitalizada ante la presencia de múltiples malformaciones congénitas, fiebre y riesgo de sepsis, por lo que ameritó tratamiento antibiótico.

Al examen físico realizado a los 6 días de vida presentó adecuada coloración cutáneo-mucosa, microcefalia, perímetro cefálico $30.6 \mathrm{~cm}$ (percentil <3), fontanela anterior de $3 \times 2 \mathrm{~cm}$ y posterior de $1 \times 2 \mathrm{~cm}$, hipotelorismo ocular, fosa nasal única, ausencia de septum nasal, hendidura de labiopalatina media, cuello corto, tórax excavatum, abdomen batracoide y hernia umbilical. En el examen neurológico se detectó hipertonía. Presentó hipertricosis en la región frontal, hombros, tórax posterior y ambos brazos (Fig. 1).

La ecografía transfontanelar evidenció parénquima cerebral adelgazado sin presencia de circunvoluciones. El sistema ventricular se encontró muy dilatado, sin la presencia de hoz cerebral, plexos coroideos no visualizados concluyentes de holoprosencefalia severa y lisencefalia. La evaluación cardiovascular mostró un corazón estructuralmente sano y la ecografía abdominorrenal no evidenció alteración. En los estudios de laboratorio se encontró hipoglucemia, hiperbilirrubinemia (a expensas de la bilirrubina indirecta) e hipocalcemia. El estudio citogenético evidenció 46,XX[34]/47,XX[6] en 40 metafases estudiadas.
Tabla 1. Hallazgos clínicos encontrados en pacientes con trisomía 13

\begin{tabular}{|c|c|c|c|}
\hline Hallazgo clínico & Frecuencia $(\%)^{9}$ & Caso 1 & Caso 2 \\
\hline $\begin{array}{l}\text { Retraso de crecimiento } \\
\text { pre y posnatal }\end{array}$ & 87 & + & + \\
\hline $\begin{array}{l}\text { Retraso psicomotor/ } \\
\text { mental profundo }\end{array}$ & 100 & NA & NA \\
\hline Microcefalia & 86 & + & + \\
\hline Holoprosencefalia & 70 & - & + \\
\hline Episodios de apnea & 58 & + & - \\
\hline Hipotonía & 48 & - & - \\
\hline Hipertonía & 26 & + & + \\
\hline $\begin{array}{l}\text { Defectos en el cuero } \\
\text { cabelludo }\end{array}$ & 75 & - & - \\
\hline Frente aplanada & 100 & + & + \\
\hline Anomalías oculares & 88 & + & - \\
\hline Hemangiomas capilares & 72 & - & - \\
\hline Hipotelorismo ocular & 83 & + & + \\
\hline Epicanto & 56 & - & - \\
\hline Labio-paladar hendido & 65 & + & + \\
\hline Paladar ojival & 72 & - & - \\
\hline Micrognatia & 84 & + & + \\
\hline $\begin{array}{l}\text { Pabellones auriculares } \\
\text { malformados }\end{array}$ & 80 & + & + \\
\hline Cuello corto & 79 & + & + \\
\hline Cardiopatía congénita & $73-91$ & + & - \\
\hline Pezones hipoplásicos & 100 & + & + \\
\hline Hernia inguinal/umbilical & 40 & - & + \\
\hline Criptorquidia & 100 & NA & NA \\
\hline Riñón poliquístico & 70 & - & - \\
\hline Hidronefrosis & 25 & - & - \\
\hline Útero bicorne & 50 & - & - \\
\hline Calcáneo prominente & 28 & + & + \\
\hline Polidactilia & 76 & - & - \\
\hline $\begin{array}{l}\text { Dedos en flexión y } \\
\text { superpuestos }\end{array}$ & 68 & + & + \\
\hline Uñas hiperconvexas & 68 & + & + \\
\hline
\end{tabular}

+: presente; -: ausente; NA: no aplica.

En la tabla 1 se muestran los hallazgos clínicos encontrados en los pacientes descritos, así como los hallazgos en pacientes con trisomía 13 reportados por Ribate, et al. ${ }^{9}$ 


\section{Discusión}

La trisomía 13 fue identificada por Patau, et al. en $1960^{3,6,10,11}$. No presenta predominio por sexo y se encuentra en el $1 \%$ de los abortos espontáneos (100 veces más que en los nacidos vivos) ${ }^{3}$. Es causada por un cromosoma 13 adicional ${ }^{10}$ y corresponde a la tercera trisomía autosómica más común en recién nacidos, después de las trisomías 21 y 18.

Dos importantes estudios con microsatélites evidenciaron que la mayoría de los casos de trisomía del 13 son de origen materno, en una proporción casi igual de errores en meiosis I y II y recombinación reducida. No obstante, se estudiaron tres casos de mosaicismo de trisomía 13 a través de una matriz de polimorfismo de nucleótido simple o único, hibridación fluorescente in situ y análisis bioinformáticos. El cromosoma 13 extra fue de origen materno en todos los casos. Dos casos fueron originados a partir de la no disyunción en meiosis I, seguida de rescate trisómico; uno de estos fue resultado de disomía uniparental segmentario en la línea disómica. El tercer caso surgió de la no disyunción de meiosis II o en la mitosis temprana, seguida de retrasos en la anafase ${ }^{12}$.

La tasa de mortalidad es aproximadamente del $50 \%$ en el primer mes de vida y del $90 \%$ durante el primer año debido a la severidad de las alteraciones en el sistema nervioso central, cardiopatías congénitas y complicaciones respiratorias ${ }^{10}$. En comparación con la forma completa, la expresividad variable en el mosaicismo de trisomía 13 puede incluir, además, pigmentación cutánea inusual y mayor supervivencia. La razón de esta variación es que el fenotipo se modifica de acuerdo con la distribución de las células con la alteración cromosómica en tejidos específicos ${ }^{3}$. Sin embargo, puede no ser atribuido completamente a este factor $^{12}$. Por lo tanto, el fenotipo y la historia natural de los pacientes con mosaicismo de trisomía del 13 no han sido bien caracterizados ${ }^{3}$.

Griffith, et al. ${ }^{1}$ presentaron 49 casos de mosaicismo de trisomía 13 (47 revisados de la literatura y dos nuevos casos). Entre las malformaciones más comunes se encontraron anomalías en el pabellón auricular, hendidura labiopalatina y diversos defectos cardíacos congénitos. La inteligencia de estos pacientes varió de normal, en seis de ellos, a retraso significativo en el resto de los casos. No existe una clara correlación entre el porcentaje de las células trisómicas y el nivel de función intelectual. Por otra parte, existe una amplia expresividad en las células dismórficas observadas entre los pacientes. Estas características dificultan el diagnóstico clínico y el pronóstico.

Inicialmente, dos casos de mosaicismo de trisomía 13 han sido descritos en Venezuela, con el 24 y el 40\% de células trisómicas, respectivamente, lo que resalta la expresividad variable. El primer caso fue un paciente de sexo masculino de 10 años, con autismo y retraso mental leve; el segundo caso fue una paciente de sexo femenino que falleció a los 3 meses de edad ${ }^{11}$. Con los dos casos expuestos en este artículo y otro caso que se había presentado previamente ${ }^{2}$, suman tres los casos diagnosticados y confirmados con estudio citogenético en la Unidad de Genética de la Universidad de Los Andes.

Aunque en estos dos nuevos casos el porcentaje de células trisómicas fue inferior a las células euploides, la presentación clínica fue severa, con el fallecimiento durante el periodo neonatal en el primer caso y con alteración estructural en el sistema nervioso central en el segundo, lo que amerita un exhaustivo seguimiento médico.

En estos dos pacientes no fue posible realizar el diagnóstico prenatal, debido a que no se llevó control prenatal del segundo paciente $y$, aunque se diagnosticó labio-paladar hendido, este hallazgo ocurrió al final de la gestación en el primer caso. No obstante, dicho diagnóstico debe establecerse para bridar un abordaje médico interdisciplinario ante la presencia de múltiples y complejas malformaciones.

En resumen, en este reporte se presentaron dos casos de mosaicismo de trisomía 13 en los que destaca la evaluación médica interdisciplinaria ante el conjunto de malformaciones congénitas que pueden evidenciarse.

A través de la realización del estudio citogenético, se pretende impartir un asesoramiento genético familiar oportuno.

\section{Responsabilidades éticas}

Protección de personas y animales. Los autores declaran que para esta investigación no se han realizado experimentos en seres humanos ni en animales.

Confidencialidad de los datos. Los autores declaran que han seguido los protocolos de su centro de trabajo sobre la publicación de datos de pacientes.

\section{Derecho a la privacidad y consentimiento infor-} mado. Los autores han obtenido el consentimiento informado de los pacientes o individuos referidos en el artículo. Este documento obra en poder del autor de correspondencia. 


\section{Conflicto de intereses}

Los autores declaran no tener ningún conflicto de intereses.

\section{Financiamiento}

Ninguno.

\section{Agradecimientos}

A la licenciada Rosalia Gumina F., directora de la Biblioteca del Instituto Autónomo Hospital Universitario de Los Andes, Universidad de Los Andes.

\section{Bibliografía}

1. Griffith $\mathrm{CB}$, Vance $\mathrm{GH}$, Weaver $\mathrm{DD}$. Phenotypic variability in trisomy 13 mosaicism: two new patients and literature review. Am J Med Genet A. 2009;149A:1346-58

2. Cammarata-Scalisi F, Araque D, Lacruz-Rengel MA, Valera-Ruíz B Mosaic trisomy 13. An Pediatr (Barc). 2013;79:402-3.
3. Pachajoa H, Meza Escobar LE. Mosaic trisomy 13 and a sacral appendage. BMJ Case Rep. 2013;2013:pii: bcr2012008150.

4. Chen CP, Chern SR, Wu PS, Chen SW, Lai ST, Chuang TY, et al. Prenatal diagnosis of low-level mosaicism for trisomy 13 at amniocentesis associated with a favorable outcome. Taiwan J Obstet Gynecol. 2017; 56:840-2.

5. Ghawi H, Engelhardt K, Dixon K, Thankaval P, Ramaciotti C, Lemler MS, et al. Sinus of valsalva aneurysm in a patient with mosaic trisomy 13 . World J Pediatr Congenit Heart Surg. 2016;2150135116682465.

6. Kunwar F, Pandya V, Bakshi SR. Constitutional mosaic trisomy 13 in two germ cell layers is different from Patau syndrome? A case report. J Clin Diagn Res. 2016;10:GD03-5.

7. Pascuzzo-Lima C, Pascuzzo-Lima MR, Fernández MA, Colmenares NM, Gavidia RV. Patrones de peso al nacer en Venezuela: influencia de la edad materna y la paridad. Rev Obstet Ginecol Venez. 2009;69:162-71.

8. Pascuzzo C, Gavidia RV, Díaz LE, Pascuzzo MR, Lima MR, Granado AR, Hernández AM, et al. Determinación de patrones de peso, talla y circunferencia cefálica al nacer en la región centroccidental de Venezuela 1995-1997. Bol Med Post. 2000;XVI:1-12.

9. Ribate MP, Pié J, Puisac B. Trisomía 13 (síndrome de Patau). Protoc Diagn Ter Pediatr. 2010;1:91-5.

10. Imataka G, Yamanouchi H, Hirato J, Eguchi M, Kojima M, Honma K, et al. Autopsy report of a 7-year old patient with the mosaic trisomy 13. Cell Biochem Biophys. 2013;67:813-7.

11. León M, Quero J, Hammond F, Estrada $P$, Pérez $M$, Pérez JC, et al. Hallazgos clínicos y citogenéticos en trisomía 13 (síndrome de Patau) reporte de 9 casos. Arch Ven Puer Ped. 2006;69:91-5.

12. Jinawath N, Zambrano R, Wohler E, Palmquist MK, Hoover-Fong J, Hamosh A, et al. Mosaic trisomy 13: understanding origin using SNP array. J Med Genet. 2011;48:323-6. 